\title{
Back to the future...
}

\author{
Professor Jonathan Sandler, ${ }^{1}$ Dr Alison Murray, ${ }_{1}^{2}$ Professor Nigel Hunt, ${ }^{3}$ Professor Kevin O'Brien, ${ }_{1}^{4}$ Professor Grant McIntyre, ${ }^{5}$ \\ Dr Richard Jones ${ }^{6}$ and Dr Helen Travess ${ }^{7}$
}

'President of the British Orthodontic Society, London, UK; ${ }^{2}$ Immediate Past President of the British Orthodontic Society, London, UK; ${ }^{3}$ Past Chair of the British Orthodontic Society and Past Chair of the Joint Committee for Postgraduate Training in Dentistry, London, UK; ${ }^{4}$ Emeritus Professor of Orthodontics, University of Manchester, UK; ${ }^{5}$ Chair of the Specialist Advisory Committee in Orthodontics,

London, UK; ${ }^{6}$ Chair of the Orthodontic Specialists Group, British Orthodontic Society, London, UK; ${ }^{7}$ Chair of the Consultant Orthodontist Group, British Orthodontic Society, London, UK.

The BDJ Upfront section includes editorials, letters, news, book reviews and interviews. Please direct your correspondence to the News Editor,

Kate Quinlan at k.quinlan@nature.com. Press releases or articles may be edited, and should include a colour photograph if possible.

S pecialist training in orthodontics has been extensively developed and refined over the last five decades, having come a long way from the old preceptorship model of the 1960s. Two seminal papers in 1982 by two eminent teachers Dick Mills ${ }^{1}$ and Bill Houston, ${ }^{2}$ described the need to move from this model towards a broader, academically structured framework. The postgraduate orthodontic courses so developed were prescient in providing both clinical and academic training. With classroom teaching taking place on a set day of the week, ${ }^{2}$ and time allocated for research towards a dissertation, the majority of the week was clinical training. This mix of academic and clinical teaching meant that universities considered these M Level, or masters courses, to be 'part-time' spread over two years (an MSc being either one year full-time or two years part-time). Fulfilling the university examination requirements, the programmes were also developed to align with the training requirements of the Royal Colleges of Surgeons and their examinations. The NHS considered the training to be part-time too, often paying $6 / 10^{\text {ths }}$ salary for the three days per week of clinical training. The university fees comprised about two months' annual salary.

Further refinement moved training to a three-year full-time course, but with full-time pay, and the specialist registrar exiting with an MSc and Membership in Orthodontics from one of the Royal Colleges. There were also changes to senior registrar training and the introduction of an exit exam at that level. An active and energentic British Orthodontic Society (BOS) invested in a virtual learning environment (VLE) to support training in line with the GDC's orthodontic curriculum. Input to the VLE came from many teachers (both NHS and University) creating 44 modules, relevant to levels from orthodontic therapists to consultants in training, as well as their orthodontic teachers.

The value of a research degree (and to some extent university input) is now being questioned by some trainees, trainers and postgraduate deans. The arguments seem to be based on cost and that other specialty training (apart from dental public health) does not have this as a requirement. If something is different, it does not mean it is wrong. The MSc is the international standard for orthodontics in many countries around the world, and its loss in the UK would do an MSc: '...makes them more critical of the quasi charlatan who has always been an embarrassment to the progress of orthodontics. If in the future the orthodontists in this country have all passed through the MSc degree course and undertaken a small investigation of their own, perhaps this might do much to dampen the swing of the pendulum which is such an unfortunate feature in our specialty?

The parlous state of orthodontic research at that time was also laid bare by David Sackett, the main exponent of the evidence-based medicine movement. His excoriating view

\section{'The issue of cost of degrees is an area where some discussion on standardisation might be helpful, perhaps led by the BOS.'}

disadvantage not only our specialists, but the training programmes that for years have been set at a level many aspire to. There is also a misunderstanding around the D Level degrees (ie professional doctorates - DDS/ DDSc/DClinDent). These were introduced by universities who wanted to give credit for three years' full-time training. This degree is flexible, and the award can be flexed to certificate, diploma, or master's level.

Some discussion on standardisation of the cost of degress might be helpful, perhaps led by the BOS. Universities are autonomous and can set their own fees, but as trainees have limited flexibility in their placements, more uniform fees would be appropriate. Why undertake a higher degree alongside specialty training? The survey by Jopson et al. in this issue indicates that most see a benefit for job prospects, career opportunities, scientific and critical appraisal skills. The latter resonates well with Mills' assertion of 40 years ago as to why all should was that trials in orthodontics lagged behind 'such treatment modalities as acupuncture, hypnosis and homeopathy and on a par with scientology, dianetics and podiatry? Looking at PubMed, there were no RCTs in orthodontics prior to 1967 but by 2005 there were 55 per year and by 2020, 174. Currently, apart from 'dental caries', orthodontics has the highest number of Cochrane reviews and the contribution through orthodontic MSc/DDS projects, has been considerable.

Whilst there are always considerations for changing the organisation of specialist training, some of the suggestions now being mooted are in danger of reversing much that has been achieved over the last 50 years.

\section{References}

1. Mills J RE. The place of research in education. $\mathrm{Br} J$ Orthod 1982; 9: 67-69.

2. Houston W J B. The evolution of a postgraduate training programme in orthodontics. Br J Orthod 1982; 9: 71-72. https://doi.org/10.1038/s41415-021-3676-6 